\title{
SCIDOC
}

\author{
International Journal of Dentistry and Oral Science (IJDOS) \\ ISSN: 2377-8075
}

\section{Correction Of Posterior Crossbite In Adolescents And Young Adults With Class I , Class II And Class III Malocclusion}

Research Article

\author{
Akshay Mohan ${ }^{1}$, Harish Babu², Nivethigaa Balakrishnan ${ }^{3}$
}

${ }^{1}$ Department of Orthodontics and Dentofacial Orthopaedics, Saveetha Dental College, Saveetha Institute of Medical and Technical Sciences, Saveetha University 162, Poonamallee High Road, Chennai-600077, Tamil Nadu, India.

${ }^{2}$ Professor, Department of Orthodontics and Dentofacial Orthopaedics, Saveetha Dental College, Saveetha Institute of Medical and Technical Sciences, Saveetha University 162, Poonamallee High Road, Chennai-600077, Tamil Nadu, India.

${ }^{3}$ Senior Lecturer, Department of Orthodontics and Dentofacial Orthopaedics, Saveetha Dental College, Saveetha Institute of Medical and Technical Sciences, Saveetha University 162, Poonamallee High Road, Chennai-600077, Tamil Nadu, India.

\section{Abstract}

The study aims to to evaluate the association between age wise distribution of patients reported with posterior crossbite in Angle's class I, II, III malocclusion and to assess the percentage distribution of various treatment modalities in posterior crossbite in class I, class II and class III malocclusion in adolescents and young adults. A sample comprising 30 subjects with posterior cross bite undergoing treatment were selected. Within the limits of this study, the percentage distribution of treatment options was determined. The hyrax appliance remains the appliance of choice in $21.43 \%$ of patients in the age group of 10 to 14 years, $18.18 \%$ of patients in the age group 15 to 19 years and bone borne anchorage being chosen for only $9.09 \%$ of patients in the age group 15 to 19 years and $20 \%$ of patients in the age group of 20 to 24 years with the help of MARPE (miniscrew assisted rapid palatal expansion) appliance. Similarly another $40 \%$ of patients in the age group of 20 to 24 years underwent rapid palatal expansion assisted with surgical corticotomy. Fixed appliance arch expansion was another mainstay of treatment choice with $64.29 \%$ of patients in the age group of 10 to 14 years, $54.55 \%$ of patients in the age group 15 to 19 years and $40 \%$ of patients in the age group of 20 to 24 years of age with transverse discrepancies undergoing arch expansion with broad arch form arch wires. The results of this study will help the clinicians to decide the best treatment option for transverse discrepancies.

Keywords: Transverse Malocclusion; Mini-Screw Assisted Rapid Palatal Expansion; Surgical Assisted Rapid Palatal Expansion; Quadhelix; Rapid Maxillary Expansion.

\section{Introduction}

Posterior dental crossbite is a malocclusion seen frequently in the mixed and permanent dentition. Posterior crossbites are characterized by a reverse transverse interarch relationship in response to a reduction in the transverse dimension of the maxillary arch. Depending on the severity of this constriction, the posterior crossbite can vary from a single tooth involvement, the usual unilateral posterior crossbite, or full crossbite. Prevalence of posterior crossbites in the primary dentition is high and represents one of the most frequent orthodontic problems in this stage of occlusal development. The epidemiologic surveys described in literature estimate that approximately $1.0 \%$ to $23.5 \%$ of children in the primary dentition show this kind of malocclusion [1-5]. Nearly $80 \%$ to $97 \%$ of all cases of unilateral posterior crossbite present a functional nature in the early stages of occlusal development $[4,6]$. That is to say, constriction of the maxillary arch is usually symmetrical and the unilateral appearance is related to mandibular deviation,which produces an asymmetry in the condyle-fossa relationship [7]. Therefore, the most frequent inter-arch expression of the maxillary constriction is the functional unilateral posterior crossbite.

In most cases, crossbite is accompanied by a mandibular shift, a so-called forced crossbite, which causes midline deviation. It is quite possible that the high incidence of constriction of the maxillary arch in the primary dentition has a strong etiologic relation-

\section{*Corresponding Author:}

Harish Babu,

Professor, Department of Orthodontics and Dentofacial Orthopaedics, Saveetha Dental College, Saveetha Institute of Medical and Technical Sciences, Saveetha University 162, Poonamallee High Road, Chennai-600077, Tamil Nadu, India. Tel: 9360575950

E-mail: harish.ortho@gmail.com

Received: September 06, 2020

Accepted: October 09, 2020

Published: October 24, 2020

Citation: Akshay Mohan, Harish Babu, Nivethigaa Balakrishnan. Correction Of Posterior Crossbite In Adolescents And Young Adults With Class I , Class II And Class III Malocclusion. Int J Dentistry Oral Sci. 2020;7(10):869-871. doi: http://dx.doi.org/10.19070/2377-8075-20000172

Copyright: Harish Babu ${ }^{\circ} 2020$. This is an open-access article distributed under the terms of the Creative Commons Attribution License, which permits unrestricted use, distribution and reproduction in any medium, provided the original author and source are credited. 
ship with frequently present sucking habits in this developmental stage, either thumb or dummy sucking, as suggested by some authors [8] associated or not to respiratory problems.

The status of the primary occlusion affects the development of the permanent occlusion. Thus a posterior crossbite is believed to be transferred from primary to permanent dentition and posterior crossbite can have long term effects on the growth and development of teeth and jaw. Studies of adolescents and adults have revealed that patients with posterior crossbite have witnessed risk to develop craniofacial mandibular disorders, showing more signs and symptoms of these problems. Early treatment of posterior crossbite was recommended to expand the maxilla, eliminate functional shift and thereby to prevent the occurrence of an abnormal transverse growth of the maxilla and the mandible leading to normal occlusal development [8-10]. The correction of transverse maxillary deficiencies is done by rapid or slow maxillary expansion. Adults with untreated unilateral posterior crossbite and skeletal asymmetry, indicate that untreated unilateral posterior crossbite in a child might lead to mandibular asymmetric development [11]. In the effective results of maxillary expansions, the relapse rate of rapid maxillary expansion was reported more in the early mixed dentition than in late mixed dentition. Some authors reported that $50 \%$ of the crossbite cases treated in the primary dentition had to be retreated in the early or late mixed dentition [12]. Epidemiological researches that show the prevalence of malocclusions in different ages or dentition stages are valuable data about the diagnosis, characteristics, etiologies of orthodontic anomalies treatment strategies, and necessary public health resources. Early treatment is often advised to normalise the occlusion for occlusal development. Postponement of treatment has claimed to result in prolonged treatment of greater complexity. In this study, we assess the various treatment options available to patients undergoing treatment for posterior crossbite.

\section{Materials and Methodology}

This retrospective cross-sectional study was done on Angle's class I, II, III malocclusion patients who reported to the department of orthodontics and dentofacial orthopedics from June 2019 to March 2020. The study was approved by the ethical committee and institutional research board (SDC/SIHEC/2020/DIASDATA/0619-0320). The dental records of 960 patients who were registered to the institution and are undergoing orthodontic correction were analysed for the study. Patients belonging to the age group of 10-24 years with Angle's class I, II, III malocclusion and posterior dental crossbite undergoing orthodontic treatment were selected for the study. Patients who had systemic illness, craniofacial deformities were excluded. 30 subjects above the age of 10-24 years with posterior crossbite undergoing orthodontic treatment were selected based on the inclusion criteria. The analysis was carried out using the statistical package for social sciences version 20.0 (SPSS Inc, Chicago, IL, USA). The percentage distribution of treatment modalities for posterior crossbite in class I, II, III malocclusion and Chi Square test were evaluated.

\section{Results and Discussion}

Previously our team had conducted clinical trials [13-19], lab animal studies [20-24] and in - vitro studies [25-27] over the past 5 years. Now we are focussing on cross sectional study from our database. Studies have shown that $50 \%$ of posterior crossbite cases treated at primary dentition had to be retreated at mixed dentition. Timely intervention by maxillary expansion in the primary dentition would decrease the risk of a posterior crossbite in permanent dentition. Rapid maxillary expansion promotes posterior skeletal effect and dental effects, thus affording the correction of a maxillary transverse deficiency. Baccetti et al., (2001) stated that a better prognosis is expected when applying this protocol at an early age. However in adulthood they found greater skeletal rigidity and consequently poor orthopedic results, Maxillary orthopedic expansion in adult patients through conventional devices has been rarely successful. The cause is commonly related to the fusion of midpalatal suture and increased interdigitation of sutures making it more resistant to splint as age progresses.

Expansion forces transmitted to teeth in traditional rapid expansion devices can create undesirable dental effects especially

Figure 1. Bar graph depicting the association between age wise distribution of patients and the treatment of posterior dental crossbite. $\mathrm{X}$ axis represents the treatment modality and $\mathrm{Y}$ axis represents the percentage of patients reporting with posterior crossbite. The age group of 10-14 years (blue) and 15-19 years (green) showed $64.29 \%$ and $54.55 \%$ treated by archwire expansion respectively. The age group of 20-24 years (brown) showed $40 \%$ treated by archwire expansion, $20 \%$ by MARPE and $40 \%$ by SARPE. Pearson Chi Square was 14.67 and p-value was 0.06 (p-value > 0.05); Statistically not significant implying that there was no major difference across age groups in association with treatment plan.

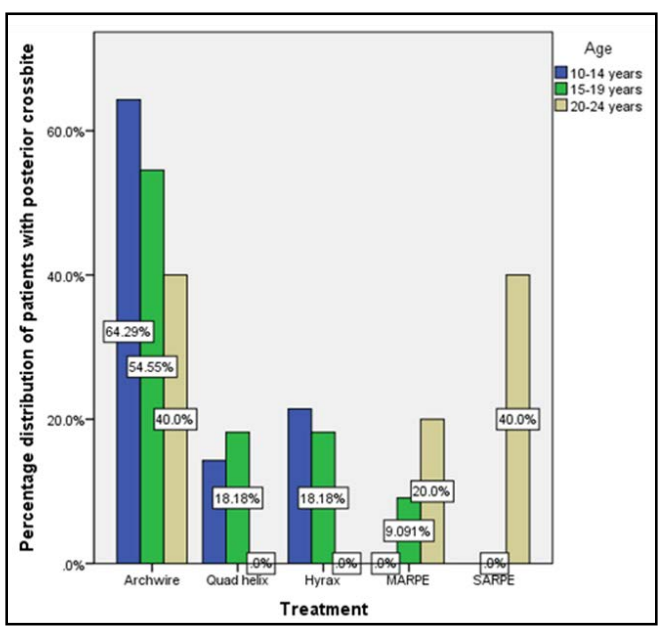


in adult patients with ossified midpalatal suture. Surgical assisted rapid palatal expansion is the treatment choice to overcome the limitation of rapid maxillary expansion by osteotomy procedure in which maxillary basal bone is separated from its main structure of skull, allowing rapid expansion with mainly skeletal effects in adults. Miniscrew assisted rapid expansion has been developed to avoid unwanted dental effects and achieve pure skeletal effects especially indicated for patients at the end of growth phase who are reluctant to the surgical procedure.

The limitation of the study was that it used only data from one center. Center-based studies have to be substituted in the absence of exact population studies. The department of orthodontics and dentofacial orthopedics receives cases from almost all over Chennai. The potential for selection bias is one of the major limitations of studies like this. Other limitations are its small sample size and lack of representation of all demography and thereby cannot be generalized to a larger population. Further studies have to be done for a larger population and can serve in better diagnosis and treatment planning.

\section{Conclusion}

Within the limits of this study, the association between age wise distribution of patients reported with posterior crossbite in Angle's class I, II, III malocclusion was assessed and it was found that there was no major difference across age groups in association with treatment plans. The hyrax appliance still remains the appliance of choice in patients in adolescents and young adults. The bone borne anchorage was chosen for late adolescents and young adults with the help of MARPE appliance. Rapid palatal expansion assisted with surgical corticotomy was the treatment of choice for adults. Fixed appliance arch expansion was another mainstay of treatment choice for adolescents and adults with transverse discrepancies undergoing arch expansion with broad arch form arch wires. The results of this study will help the clinicians to decide the best treatment option for a crossbite case. The limitation of the study was that it used only data from one center. Center-based studies have to be substituted in the absence of exact population studies. Other limitations are its small sample size and lack of representation of all demography and thereby cannot be generalized to a larger population. Further studies have to be done for a larger population and can serve in better diagnosis and treatment planning.

\section{Acknowledgements}

All the authors have equally contributed towards the study.

\section{References}

[1]. Carvalho JC, Vinker F, Declerck D. Malocclusion, dental injuries and dental anomalies in the primary dentition of Belgian children. Int J Paediatr Dent. 1998 Jun; 8(2): 137-41. PMID: 9728099.

[2]. Farsi NM, Salama FS. Characteristics of primary dentition occlusion in a group of Saudi children. Int J Paediatr Dent. 1996 Dec; 6(4): 253-9. PMID: 9161193.

[3]. Foster TD, Hamilton MC, Lavelle CL. Dentition and dental arch dimensions in British children at the age of 212 to 3 years. Archives of oral biology. 1969 Sep 1; 14(9): 1031-40.
[4]. Holm AK. Oral health in 4-year-old Swedish children. Community Dent Oral Epidemiol. 1975 Feb; 3(1): 25-33. PMID: 234319.

[5]. Infante PF. An epidemiological study of deciduous tooth emergence and growth in white and black children of southeastern Michigan. Ecology of Food and Nutrition. 1975 Jan 1; 4(2): 117-24.

[6]. Kurol J, Berglund L. Longitudinal study and cost-benefit analysis of the effect of early treatment of posterior cross-bites in the primary dentition. Eur J Orthod. 1992 Jun; 14(3): 173-9. PMID: 1628683.

[7]. Hesse KL, Artun J, Joondeph DR, Kennedy DB. Changes in condylar postition and occlusion associated with maxillary expansion for correction of functional unilateral posterior crossbite. Am J Orthod Dentofacial Orthop. 1997 Apr; 111(4): 410-8. PMID: 9109586.

[8]. Modéer T, Odenrick L, Lindner A. Sucking habits and their relation to posterior cross-bite in 4-year-old children. Scand J Dent Res. 1982 Aug; 90(4): 323-8. PMID: 6957971.

[9]. Christie KF, Boucher N, Chung CH. Effects of bonded rapid palatal expansion on the transverse dimensions of the maxilla: a cone-beam computed tomography study. Am J Orthod Dentofacial Orthop. 2010 Apr; $137(4$ Suppl): S79-85. PMID: 20381765.

[10]. Harrison JE, Ashby D. Orthodontic treatment for posterior crossbites. Cochrane Database Syst Rev. 2001; (1): CD000979. PMID: 10796568.

[11]. Kutin G, Hawes RR. Posterior cross-bites in the deciduous and mixed dentitions. Am J Orthod. 1969 Nov; 56(5): 491-504. PMID: 5261162.

[12]. Bartzela T, Jonas I. Long-term stability of unilateral posterior crossbite correction. Angle Orthod. 2007 Mar; 77(2): 237-43. PMID: 17319757.

[13]. Sivamurthy G, Sundari S. Stress distribution patterns at mini-implant site during retraction and intrusion--a three-dimensional finite element study. Prog Orthod. 2016; 17: 4. PMID: 26780464.

[14]. Viswanath A, Ramamurthy J, Dinesh SP, Srinivas A. Obstructive sleep apnea: awakening the hidden truth. Niger J Clin Pract. 2015 Jan-Feb; 18(1): 1-7. PMID: 25511335.

[15]. Felicita AS. Quantification of intrusive/retraction force and moment generated during en-masse retraction of maxillary anterior teeth using miniimplants: A conceptual approach. Dental Press J Orthod. 2017 Sep-Oct; 22(5): 47-55. PMID: 29160344.

[16]. Samantha C, Sundari S, Chandrasekhar S, Sivamurty G, Dinesh S. Comparative Evaluation of Two Bis-GMA Based Orthodontic Bonding Adhesives - A Randomized Clinical Trial. J Clin Diagn Res. 2017 Apr; 11(4): ZC40ZC44. PMID: 28571259.

[17]. Krishnan S, Pandian S, Kumar S A. Effect of bisphosphonates on orthodontic tooth movement-an update. J Clin Diagn Res. 2015 Apr; 9(4): ZE01-5. PMID: 26023659

[18]. Vikram NR, Prabhakar R, Kumar SA, Karthikeyan MK, Saravanan R. Ball Headed Mini Implant. J Clin Diagn Res. 2017 Jan; 11(1): ZL02-ZL03. PMID: 28274084.

[19]. Kamisetty SK, Verma JK, Arun, Sundari S, Chandrasekhar S, Kumar A. SBS vs Inhouse Recycling Methods-An Invitro Evaluation. J Clin Diagn Res. 2015 Sep; 9(9): ZC04-8. PMID: 26501002.

[20]. Rubika J, Felicita AS, Sivambiga V. Gonial angle as an indicator for the prediction of growth pattern. World J Dent. 2015; 6(3): 161-3.

[21]. Jain RK, Kumar SP, Manjula WS. Comparison of intrusion effects on maxillary incisors among mini implant anchorage, $\mathrm{j}$-hook headgear and utility arch. J Clin Diagn Res. 2014 Jul; 8(7): ZC21-4. PMID: 25177631.

[22]. Pandian KS, Krishnan S, Kumar SA. Angular photogrammetric analysis of the soft-tissue facial profile of Indian adults. Indian J Dent Res. $2018 \mathrm{Mar}-$ Apr; 29(2): 137-143. PMID: 29652003.

[23]. Ramesh Kumar KR, Shanta Sundari KK, Venkatesan A, Chandrasekar S. Depth of resin penetration into enamel with 3 types of enamel conditioning methods: a confocal microscopic study. Am J Orthod Dentofacial Orthop. 2011 Oct; 140(4): 479-85. PMID: 21967934.

[24]. Felicita AS. Orthodontic management of a dilacerated central incisor and partially impacted canine with unilateral extraction - A case report. Saudi Dent J. 2017 Oct; 29(4): 185-193. PMID: 29033530.

[25]. Felicita AS, Chandrasekar S, Shanthasundari KK. Determination of craniofacial relation among the subethnic Indian population: a modified approach - (Sagittal relation). Indian J Dent Res. 2012 May-Jun; 23(3): 30512. PMID: 23059564

[26]. Dinesh SP, Arun AV, Sundari KK, Samantha C, Ambika K. An indigenously designed apparatus for measuring orthodontic force. J Clin Diagn Res. 2013 Nov; 7(11): 2623-6. PMID: 24392423.

[27]. Felicita AS. Orthodontic extrusion of Ellis Class VIII fracture of maxillary lateral incisor - The sling shot method. Saudi Dent J. 2018 Jul; 30(3): 265269. PMID: 29942113. 